\title{
Awareness and Knowledge on Blood / Body Fluid Spill Management Among Health Care Providers
}

\author{
Kirthick Kumaran A. $S^{1}$, Kavitha $S^{2 *}$, Archana Santhanam ${ }^{3}$, V. Vishnupriya ${ }^{4}$ and Gayathri $R^{5}$ \\ ${ }^{1}$ Saveetha Dental College and Hospital, Saveetha Institute of Medical \\ and Technical science (SIMATS) Saveetha University, Chennai, India. \\ ${ }^{2,4,5}$ Department of Biochemistry Saveetha Dental College and Hospital, Saveetha Institute of \\ Medical and Technical Sciences (SIMATS) Saveetha University, Chennai, India. \\ ${ }^{3}$ Department of Oral Pathology, Saveetha Dental College and Hospital, Saveetha Institute of \\ Medical and Technical Sciences (SIMATS) Saveetha University, Chennai, India \\ Corresponding author email: kavithas.sdc@saveetha.com
}

\section{ABSTRACT}

Blood/ body fluid spill management is the standard principle application, which includes the use of personal protective equipment (PPE) as applicable, spills should be cleared up before the area is cleaned. Adding cleaning liquid to spills increases the size of the spill and it should be avoided effectively. Health care services should have management systems in place for dealing with blood and body substance spills. A descriptive cross-sectional study was conducted among healthcare providers to access their knowledge and awareness on blood/body fluid spill management. The total number of people involved was 119. Self-administered questionnaire of close ended questions was prepared and distributed through the online survey "GOOGLE FORMS ". In the present study about $58 \%$ of the population know about the steps followed in the blood/body fluid spill management, and $42 \%$ of the population don't know the steps followed in the blood/body fluid spill management. Regarding the importance of blood/body fluid spill management, $42 \%$ of them said it is important, $48.7 \%$ of them said it is not very important as well as not less important, and $9.2 \%$ of them said it is not at all important. In the present study, knowledge and awareness on blood/body fluid spill management is moderate among health care providers. For further augmentation, awareness should be created through various programs about the risk factors of blood/body fluid spill management.

KEY WORDS: SPILL MANAGEMENT, BLOOD OR BODY FLUID, AWARENESS, PROTOCOL, HEALTH CARE PROVIDERS.

\section{INTRODUCTION}

Blood/ body fluid spill management is the standard principle application, which includes the use of personal protective equipment (PPE) as applicable, spills should be cleared up before the area is cleaned. Adding cleaning liquid to spills increases the size of the spill and it should be avoided effectively. Health care services should have management systems in place for dealing with blood and body substance spills. The type of spills is sputum, vomit, faeces, urine,

Biosc Biotech Res Comm P-ISSN: 0974-6455 E-ISSN: 2321-4007

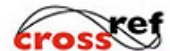

Identifiers and Pagination

Year: 2021 Vol: 14 No (10) Special Issue

Pages: $97-103$

This is an open access article under Creative

Commons License Attribn 4.0 Intl (CC-BY).

DOI: $h t t p: / / d x$.doi.org/10.21786/bbrc/14.10.16 blood or laboratory culture. The pathogens are more likely to be involved in these different types of spills for example, stool samples may contain viruses, bacteria or protozoan pathogens, whereas sputum may contain mycobacterium tuberculosis. It is used to dispose of the properly absorbed body fluids, and wipes area water detergent until it is visibly clean, washing hands with soap and water with single use towels is always recommended. Body fluids are a global issue today.

The defined solid fluid is a liquid waste intermediate product generated through diagnosis treatment. Dental offices generate a number of hazardous wastes which determines the environment is not properly managed. Training problems which were launched, increases the capacity of occupational health nurses which was designed in implant work places. Increased risk factor, epidermally analysis the immobility labour increased in temperature excessive moisture during birth. Disposable absorb sheets must comfort and not restrict.

\section{Article Information}

Received: $11^{\text {th }}$ Aug 2021

Accepted after revision: $23^{\text {rd }}$ Oct 2021 
Use of a mask, gown to clear the spilled blood screening is considered to be non-infectious (Martin et al., 2004; Wu et al., 2007; Nkoko et al., 2014; Nkoko et al., 2014; Ranjan et al., 2016).

Previous research on various aspects like nano technology (Wu et al., 2019; Ke et al., 2019) phytochemistry (Chen et al., 2019; Li et al., 2020), pharmacology (Rengasamy et al., 2016; Shukri et al., 2016), cancer technology (Menon et al., 2016; Jainu et al., 2018; Rengasamy et al., 2018; Ramya et al., 2018; Wang et al., 2019), biotechnology (Ma et al., 2019; Mohan et al., 2015) as well as biochemical and molecular toxicology (Gan et al., 2019; Ponnulakshmi et al., 2019) were conducted by our team.

Figure 1: This pie chart represents the percentage distribution of knowledge and awareness on the steps in blood/ body fluid spill management. Blue color represents yes and red color represents no. Majority of the participants $(58.18 \%)$ were aware.

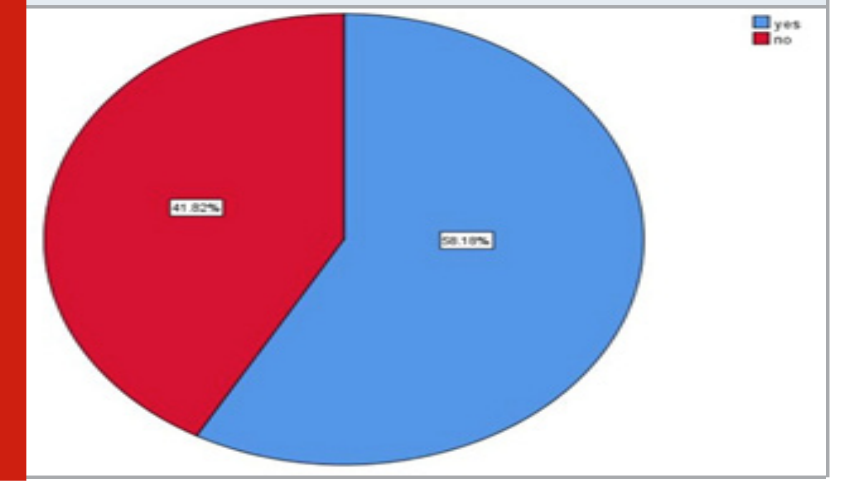

Figure 2: This pie chart represents the percentage distribution of knowledge and awareness about spill management as important for infection control. Blue color represents yes and red color represents no. Majority of the respondents $(58.18 \%)$ were not aware of infection control.

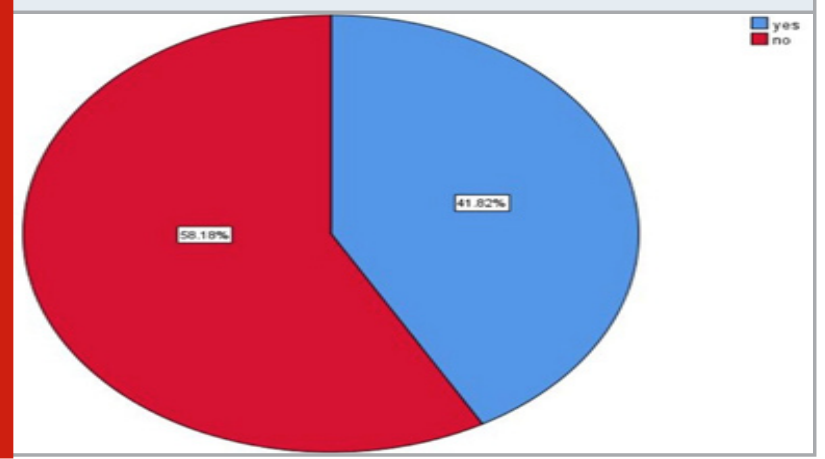

Previously our team has a rich experience in working on various research projects across multiple disciplines (Gheena and Ezhilarasan, 2019; Ke et al., 2019; Malli Sureshbabu et al., 2019; Mehta et al., 2019; Samuel et al., 2019; Sharma et al., 2019; Varghese et al., 2019; Venu et al., 2019; Vignesh et al., 2019; Jain et al., 2019; Jose et al., 2020; Krishnaswamy et al., 2020; Muthukrishnan et al., 2020; Samuel et al., 2020; Sathish and Karthick, 2020). Now the growing trend in this area motivated us to pursue this project. The aim of the present study was to assess and create awareness on the blood/body fluid spill management.

Figure 3: This pie chart represents the percentage distribution on the blood/body fluid carried out by whom. Blue color represents nurses and red color represents housekeeping. Majority of the respondents (55.45\%) think that nurses carry out blood/body fluid spill management.

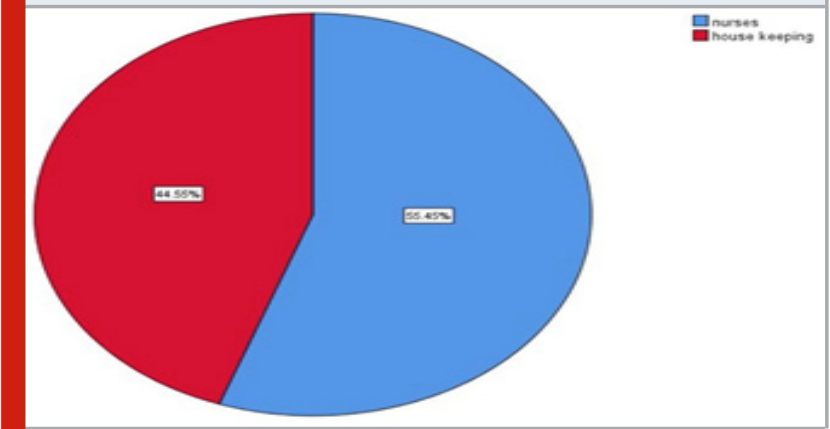

Figure 4: This pie chart graph represents the percentage distribution on the use of disinfectant before or after spill management. Blue color represents after cleaning the floor with disinfectant and red color represents before cleaning the floor with disinfectant. Majority of the respondents $(60.91 \%)$ responded as disinfectant is used after spill management.

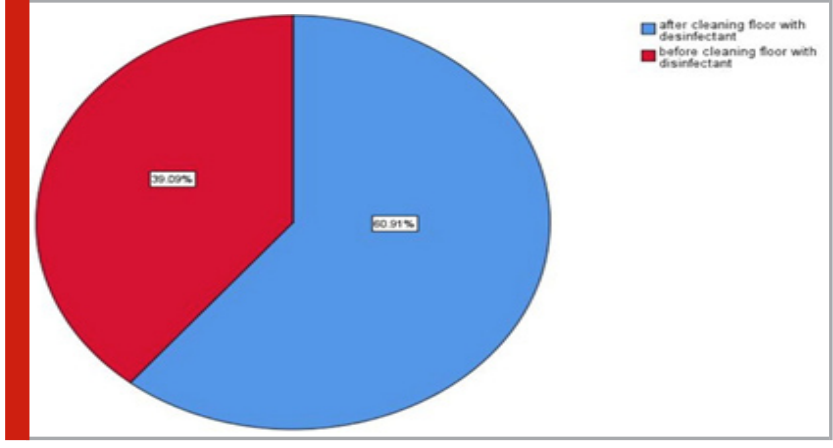

Figure 5: This pie chart represents the percentage distribution on the usage of sodium hypochlorite. Blue color represents freshly prepared and red color represents an already prepared solution. Majority of the respondents $(60 \%)$ used freshly prepared sodium hypochlorite solution.

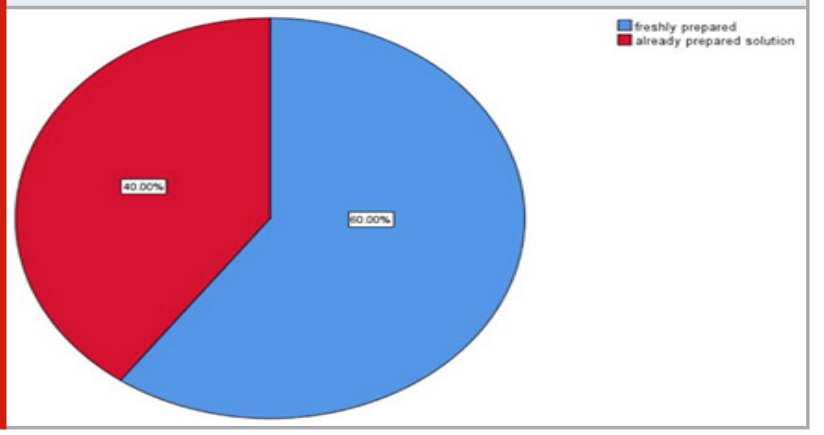




\section{MATERIAL AND METHODS}

A descriptive cross-sectional study was conducted among healthcare providers to access their knowledge and awareness on blood/body fluid spill management. Approval was obtained from the institutional review board. Simple convenient random sampling was done. The total number of people were involved 100. Self-administered questionnaire of close ended questions was prepared related to blood/body fluid spill management among health care providers through the online survey "Google Forms". The total number of questions was 15 , the type of questions was closed by last questions, yes or no type. The data were manipulated and cleared in the excel sheet. Data were of represented by pie chart and bar graph table. The statistical analysis was done by SPSS software, and chi square test. The independent variables were age and gender. The dependent variables were knowledge, awareness and procedures. Type of analytics was used here which was percentage analysis. Step were followed here software analysis, data collection analysis and interpretation.

Figure 6: This pie chart represents the percentage distributions of the biochemical waste bin used. Blue color represents yellow and red color represents black. Majority of the respondents $(\mathbf{5 4 . 5 5 \%})$ responded as black biochemical waste bins.

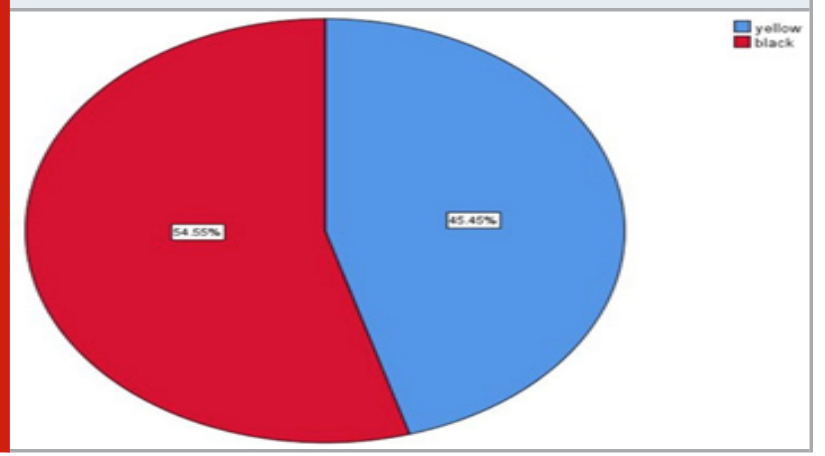

Figure 7: This pie chart represents the percentage distribution regarding washing the hands with soap and water for 20-30 seconds is the first step. Blue colour represents true and red colour represents false. Majority of the respondents $(55.45 \%)$ first wash their hands with soap and water for 20-30 seconds.

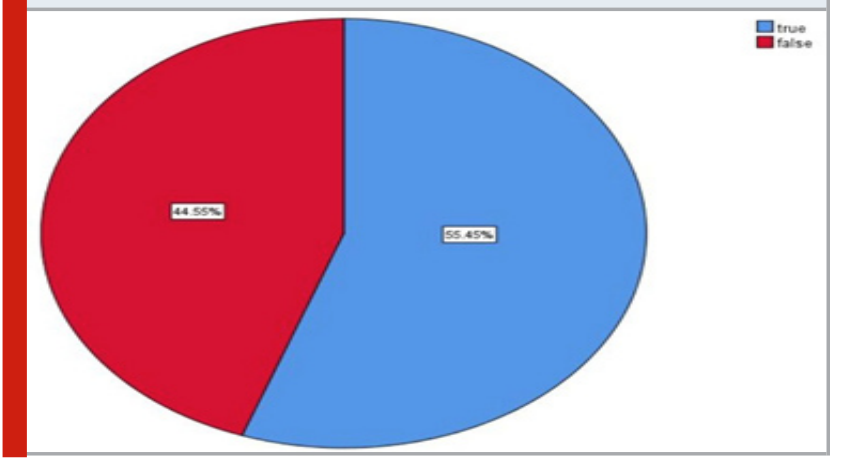

Figure 8: This pie chart represents the percentage distribution on the importance of blood/body fluid spill management. Blue colour represents extremely important and red colour represents not at all important. Majority of the respondents $(52.73 \%)$ felt it is not at all important.

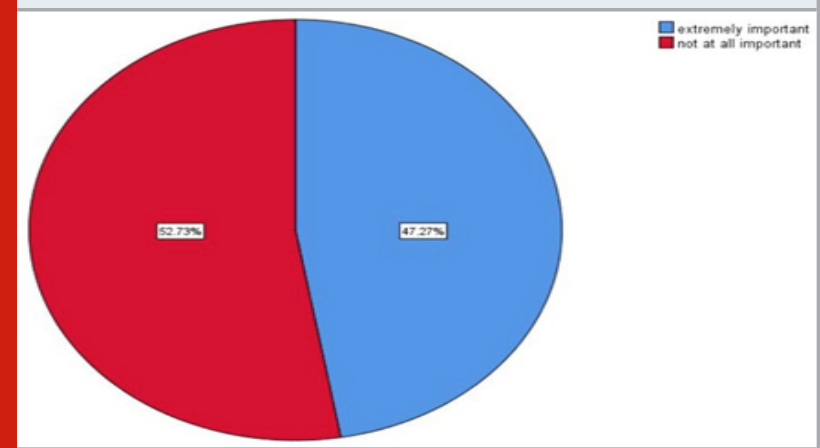

Figure 9: This pie chart represents the percentage distribution of the incident reported to infection control nurses. Blue colour represents yes and red colour represents no. Majority of the respondents $(50.91 \%)$ report incidents to infection control disease.

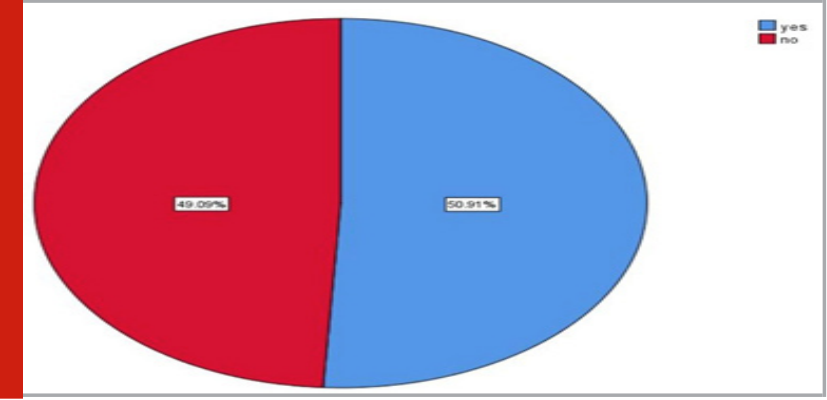

Figure 10: This pie chart represents the percentage distribution on wearing gloves. Blue colour represents true and red colour represents false. Majority of the respondents $(53.64 \%)$ do not wear gloves during blood/body fluid spill management.

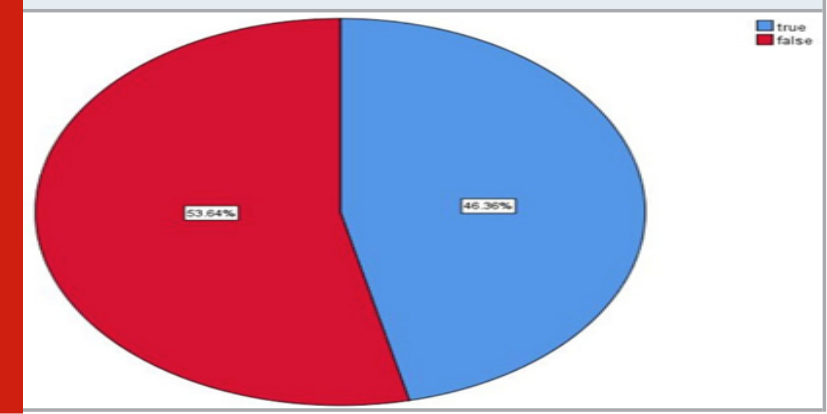

RESULTS AND DISCUSSION

The study population included the health care providers. In the present study, (figure 1) showed $58.18 \%$ know the steps in blood/body fluid spill management and $41.82 \%$ don't know the steps. $41.82 \%$ of the participants was aware and $58.1 \%$ were not aware that spill management is important for infection control (figure 2). Figure 3 showed that 55.45 
$\%$ were responded as blood/ body fluid spill management was carried out by nurses and $44.55 \%$ as carried out by housekeeping. $60.91 \%$ of the health care providers responded that blood body fluid spill management was carried after cleaning the floor with disinfectant, 39.09\% responded as before cleaning the floor with disinfectant (figure 4). In figure $5,60 \%$ of the respondents said that they use freshly prepared sodium hypochlorite and $40 \%$ said it is not a freshly prepared solution. Sata et al, 2004 also had a similar result (Sata et al., 1996). 54.55\% agreed that yellow biochemical waste bin was used in blood body fluid spill management and $45.45 \%$ said that it is black biochemical waste bin (figure 6). Figure 7 showed that $51.82 \%$ are aware that washing the hands with soap and water is the first step and $48.18 \%$ of them are not aware of it.

Figure 11: This pie chart represents the percentage distribution on the protocol training in blood/body fluid spill management. Blue colour represents yes and red colour represents no. Majority of the respondents $(66.36 \%)$ were not trained for the protocol.

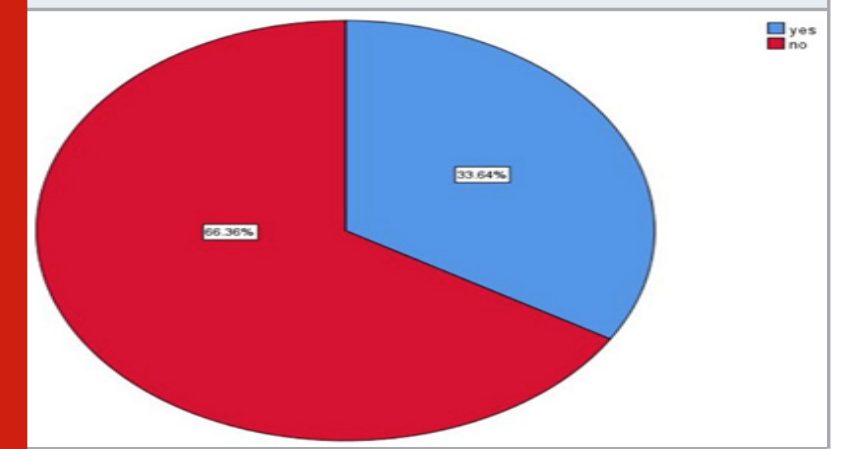

Figure 12: Figure showing the association of responses based on age to the steps involved in the blood/body fluid management. $\mathrm{X}$ axis represents the age group and $\mathrm{Y}$ axis represents the number of participants of which blue colour indicates yes and red colour indicates no. Majority of the participants in the age group of less than 20 years (40 participants) were aware of the steps in blood/body fluid spill management. However, the difference among the age groups is statistically not significant (Chi square value-2.788, p value- $0.594(>0.05)$ hence not significant)

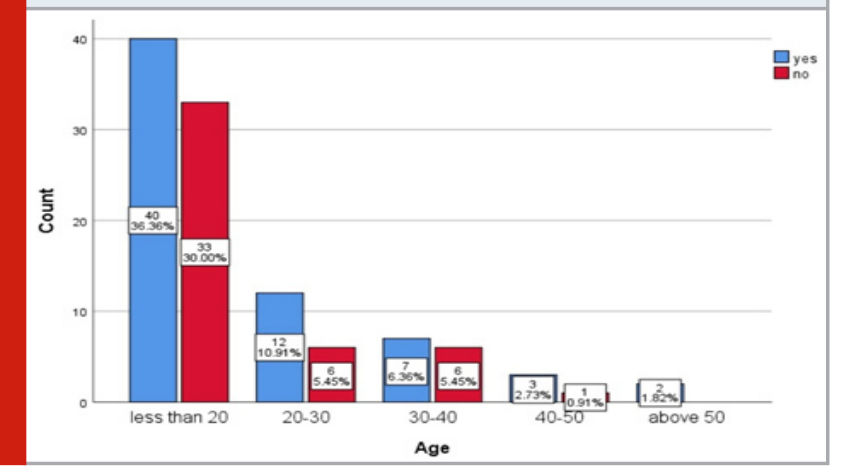

Figure 8 showed that $39.09 \%$ of the population believed that blood /body fluid spill management is extremely important, $51.82 \%$ felt it is not very important and $9.09 \%$ felt it is not at all important. Figure 9 showed that $46.36 \%$ of them said wearing gloves is the first step and $53.64 \%$ of them said wearing gloves is not the first step during the spill management. Figure 10 showed that $59.09 \%$ of the respondents follow the procedures in blood/body fluid spill management and $40.91 \%$ of them don't follow the procedure in blood/body fluid spill management. $66.36 \%$ of the respondents are not trained for the protocol and 33.64\% of them are trained for the protocol (figure 11).

Figure 13: showing the association of responses based on age to the blood/body fluid spill management importance to infection control. $X$ axis represents the age group and $Y$ axis represents the number of participants of which blue colour indicates yes and red colour indicated no. Majority of the participants in the age group of less than 20 years (38 participants) were not aware of blood/body fluid spill management importance to infection control. (Chi-square value-10.727, p-value-0.030( $<0.05)$ hence significant $)$.

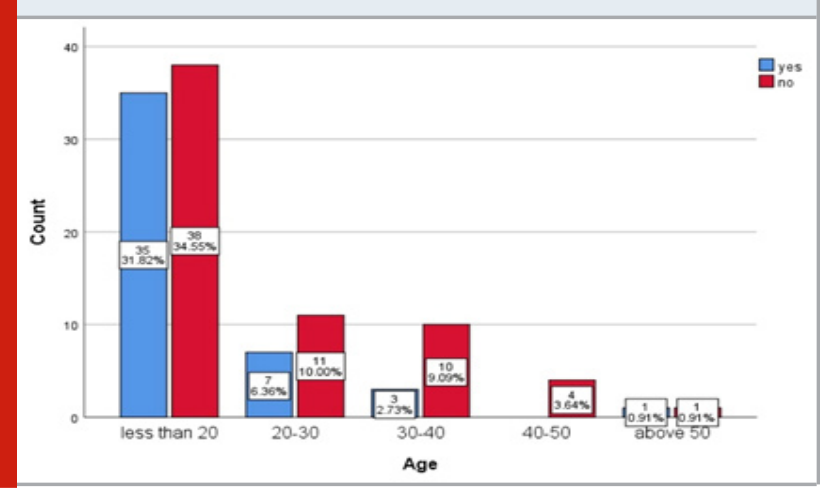

Figure 14: showing the association of responses based on age to the steps sodium hypochlorite used in the blood/body fluid management. $X$ axis represents the age group and $Y$ axis represents the number of participants of which blue colour indicates freshly prepared and red colour indicates already prepared solution. Majority of the participants in the age group of less than 20 years (46 participants) used freshly prepared sodium hypochlorite solution. However, the difference is statistically not significant (Chi-square value4.058, p-value- 0.398 ( $>0.05)$ hence not significant)

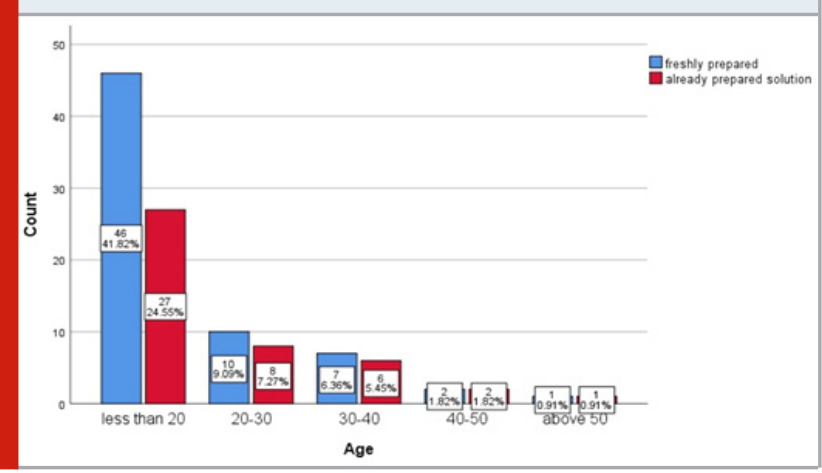

Pearson Chi square test was done in association with the age of the respondents (Figure 12-16). 58.18\% of the people are of the steps involved in spill management, of which $36.36 \%$ constitutes people less than 20 years ( $\mathrm{P}$ value- 0.594 
$(>0.05)$ which is statistically insignificant) (figure 12). Out of the $58.18 \%$ of the participants who said that blood/body fluid spill management was important for infection control, $34.55 \%$ constituted people who belong to less than 20 years (P value-0.030 $(-<0.05)$ which is statistically significant) (figure 13).

Figure 15: showing the association of responses based on age to the procedures in the blood/ body fluid management. $\mathrm{X}$ axis represents the age group and $\mathrm{Y}$ axis represents the number of participants of which blue colour indicates true and red colour indicates false. Majority of the participants in the age group of less than 20 years (41 participants) do not follow the procedures in blood/body fluid spill management. However, the difference is statistically not significant (Chi- square value-6.401, $\mathrm{p}$-value-0.171(>0.05) hence not significant).

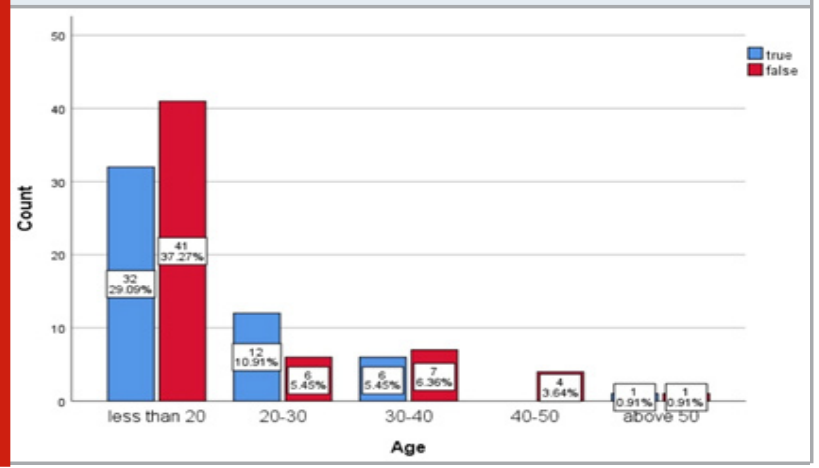

Figure 16: Bar chart showing the association of responses based on age to the protocol training in the blood/ body fluid management. $X$ axis represents the age group and $Y$ axis represents the number of participants of which blue colour indicates yes and red colour indicates no. Majority of the participants in the age group of less than 20 years (50 participants) were not trained for any protocol in blood/ body fluid spill management. However, the difference is statistically not significant (Chi-square value-1.718, p-value$0.787(>0.05)$ hence not significant)

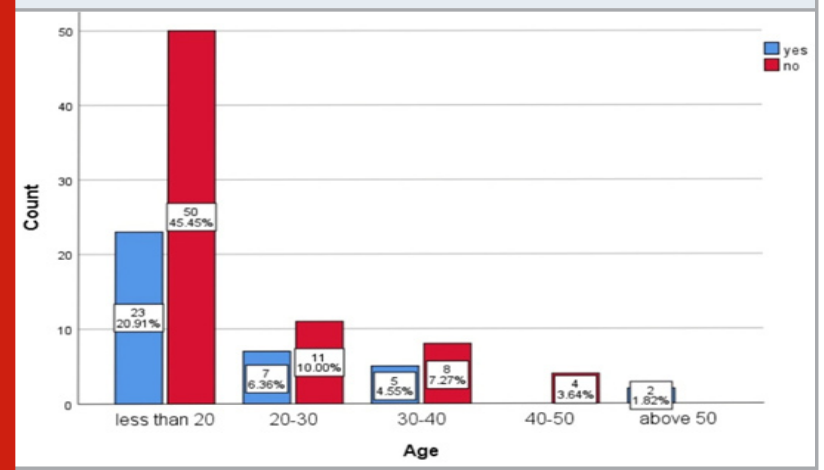

This study was showed that there is a significant association between age and the awareness on the fact that spill management is important for infection control. Out of the $58 \%$ of the participants who said sodium hypochlorite used in blood/ body fluid spill management is freshly prepared, $41.82 \%$ of the people belong to less than 20 years ( $\mathrm{P}$ value-
$0.398(->0.05)$ which is statistically insignificant) (figure 14). $59.09 \%$ of the participants said that they follow the procedures in blood/body fluid spill management ( $\mathrm{p}$ value$0.171(->0.05)$ which is statistically insignificant) (figure 15). $65.5 \%$ of the participants said that they are not trained for any protocol in blood/body fluid spill management, of which $45.45 \%$ of the people belong to less than 20 years $(\mathrm{P}$ value-0.787 (>0.05) which was statistically insignificant) (figure16). The limitations of this study are less sample size, and inclusion of only one type population.

Our institution is passionate about high quality evidence based research and has excelled in various fields (Pc et al., 2018; Ramesh et al., 2018; Ezhilarasan et al., 2019; Ramadurai et al., 2019; Sridharan et al., 2019; Vijayashree, 2019; Mathew et al., 2020). We hope this study adds to this rich legacy.

\section{CONCLUSION}

In the present study, knowledge and awareness on blood/ body fluid spill management is moderate among health care providers. For further augmentation, awareness should be created through various programs about the risk factors of blood/body fluid spill management.

\section{REFERENCES}

Chen, F. et al. (2019). 6-shogaol, an active constituents of ginger prevents UVB radiation mediated inflammation and oxidative stress through modulating $\mathrm{NrF} 2$ signaling in human epidermal keratinocytes (HaCaT cells). Journal of photochemistry and photobiology. B, Biology, 197, p. 111518.

Ezhilarasan, D., Apoorva, V. S. and Ashok Vardhan, N. (2019). Syzygium cumini extract induced reactive oxygen species-mediated apoptosis in human oral squamous carcinoma cells. Journal of oral pathology \& medicine: official publication of the International Association of Oral Pathologists and the American Academy of Oral Pathology, 48(2), pp. 115-121.

Gan, H. et al. (2019). Zingerone induced caspase-dependent apoptosis in MCF-7 cells and prevents 7,12-dimethylbenz(a)anthracene-induced mammary carcinogenesis in experimental rats. Journal of Biochemical and Molecular Toxicology. doi: 10.1002/ jbt.22387.

Gheena, S. and Ezhilarasan, D. (2019). Syringic acid triggers reactive oxygen species-mediated cytotoxicity in HepG2 cells. Human \& experimental toxicology, 38(6), pp. 694-702.

Jain, S. et al. (2019). Evaluation of Three-Dimensional Changes in Pharyngeal Airway Following Isolated Lefort One Osteotomy for the Correction of Vertical Maxillary Excess: A Prospective Study. Journal of maxillofacial and oral surgery, 18(1), pp. 139-146.

Jainu, M., Priya, V. and Mohan, S. (2018). Biochemical 
evidence for the antitumor potential of Garcinia mangostana Linn. On diethylnitrosamine-induced hepatic carcinoma. Pharmacognosy Magazine, p. 186. doi: 10.4103/ pm.pm_213_17.

Jose, J., Ajitha and Subbaiyan, H. (2020). Different treatment modalities followed by dental practitioners for Ellis class 2 fracture - A questionnaire-based survey. The open dentistry journal, 14(1), pp. 59-65.

Ke, Y. et al. (2019). Photosynthesized gold nanoparticles from Catharanthus roseus induces caspase-mediated apoptosis in cervical cancer cells (HeLa). Artificial cells, nanomedicine, and biotechnology, 47(1), pp. 19381946.

Krishnaswamy, H. et al. (2020). Investigation of air conditioning temperature variation by modifying the structure of passenger car using computational fluid dynamics. Thermal science, 24(1 Part B), pp. 495-498.

Li, Z. et al. (2020). Apoptotic induction and anti-metastatic activity of eugenol encapsulated chitosan nanopolymer on rat glioma C6 cells via alleviating the MMP signaling pathway. Journal of photochemistry and photobiology. B, Biology, 203, p. 111773.

Ma, Y. et al. (2019). Sesame Inhibits Cell Proliferation and Induces Apoptosis through Inhibition of STAT-3 Translocation in Thyroid Cancer Cell Lines (FTC-133). Biotechnology and Bioprocess Engineering, pp. 646-652. doi: 10.1007/s12257-019-0151-1.

Malli Sureshbabu, N. et al. (2019). Concentrated Growth Factors as an Ingenious Biomaterial in Regeneration of Bony Defects after Periapical Surgery: A Report of Two Cases. Case reports in dentistry, 2019, p. 7046203.

Martin, P. H. et al. (2004). Development of a GISbased spill management information system. Journal of hazardous materials, 112(3), pp. 239-252.

Mathew, M. G. et al. (2020). Evaluation of adhesion of Streptococcus mutans, plaque accumulation on zirconia and stainless steel crowns, and surrounding gingival inflammation in primary. Clinical oral investigations.

Mehta, M. et al. (2019). Oligonucleotide therapy: An emerging focus area for drug delivery in chronic inflammatory respiratory diseases. Chemico-biological interactions, 308, pp. 206-215.

Menon, A., Priya, P. V. and Gayathri, R. (2016). Preliminary phytochemical analysis and cytotoxicity potential of pineapple extract on oral cancer cell lines. Asian J Pharm Clin Res, 9, pp. 140-143.

Mohan, S. K., Veeraraghavan, V. P. and Jainu, M. (2015). Effect of pioglitazone, quercetin and hydroxy citric acid on extracellular matrix components in experimentally induced non-alcoholic steatohepatitis. Iranian journal of basic medical sciences, 18(8), pp. 832-836.

Muthukrishnan, S. et al. (2020). Support vector machine for modelling and simulation of heat exchangers. Thermal science, 24(1 Part B), pp. 499-503.

Nkoko, L. et al. (2014). Reducing the risks to health care workers from blood and body fluid exposure in a small rural hospital in Thabo-Mofutsanyana, South Africa. Workplace health \& safety, 62(9), pp. 382-388.

Pc, J., Marimuthu, T. and Devadoss, P. (2018). Prevalence and measurement of anterior loop of the mandibular canal using CBCT: A cross sectional study. Clinical implant dentistry and related research. Available at: https:// europepmc.org/article/med/29624863.

Ponnulakshmi, R. et al. (2019). In silico and in vivo analysis to identify the antidiabetic activity of beta sitosterol in adipose tissue of high fat diet and sucrose induced type-2 diabetic experimental rats', Toxicology mechanisms and methods, 29(4), pp. 276-290.

Ramadurai, N. et al. (2019). Effectiveness of $2 \%$ Articaine as an anesthetic agent in children: randomized controlled trial. Clinical oral investigations, 23(9), pp. 3543-3550.

Ramesh, A. et al. (2018). Comparative estimation of sulfiredoxin levels between chronic periodontitis and healthy patients - A case-control study. Journal of periodontology, 89(10), pp. 1241-1248.

Ramya, G., Priya, V. V. and Gayathri, R. (2018). Cytotoxicity of strawberry extract on oral cancer cell line. Asian J Pharm Clin Res, 11, pp. 353-355.

Ranjan, R. et al. (2016). Awareness about biomedical waste management and knowledge of effective recycling of dental materials among dental students. Journal of International Society of Preventive \& Community Dentistry, 6(5), pp. 474-479.

Rengasamy, G. et al. (2016). Characterization, Partial Purification of Alkaline Protease from Intestinal Waste of Scomberomorus Guttatus and Production of Laundry Detergent with Alkaline Protease Additive. Indian Journal of Pharmaceutical Education and Research, 50(2s). Available at: https://www.ijper.org/article/413 (Accessed: 4 June 2020).

Rengasamy, G. et al. (2018). Cytotoxic and apoptotic potential of Myristica fragrans Houtt. (mace) extract on human oral epidermal carcinoma KB cell lines. Brazilian Journal of Pharmaceutical Sciences. doi: 10.1590/s217597902018000318028.

Samuel, M. S. et al. (2019). Efficient removal of Chromium (VI) from aqueous solution using chitosan grafted graphene oxide (CS-GO) nanocomposite. International journal of biological macromolecules, 121, pp. 285-292. Samuel, S. R., Acharya, S. and Rao, J. C. (2020). School Interventions-based Prevention of Early-Childhood Caries among 3-5-year-old children from very low socioeconomic status: Two-year randomized trial. Journal of public health dentistry, 80(1), pp. 51-60.

Sata, T. et al. (1996). Change of anion exchange membranes in an aqueous sodium hydroxide solution 
at high temperature. Journal of Membrane Science, pp. 161-170. doi: 10.1016/0376-7388(95)00292-8.

Sathish, T. and Karthick, S. (2020). Wear behaviour analysis on aluminium alloy 7050 with reinforced $\mathrm{SiC}$ through taguchi approach. Journal of Japan Research Institute for Advanced Copper-Base Materials and Technologies, 9(3), pp. 3481-3487.

Sharma, P. et al. (2019). Emerging trends in the novel drug delivery approaches for the treatment of lung cancer. Chemico-biological interactions, 309, p. 108720.

Shukri, N. M. M. et al. (2016). Awareness in childhood obesity. Research Journal of Pharmacy and Technology, p. 1658. doi: 10.5958/0974-360x.2016.00334.6.

Sridharan, G. et al. (2019). Evaluation of salivary metabolomics in oral leukoplakia and oral squamous cell carcinoma. Journal of oral pathology \& medicine: official publication of the International Association of Oral Pathologists and the American Academy of Oral Pathology, 48(4), pp. 299-306.

Varghese, S. S., Ramesh, A. and Veeraiyan, D. N. (2019). Blended Module-Based Teaching in Biostatistics and Research Methodology: A Retrospective Study with Postgraduate Dental Students. Journal of dental education, 83(4), pp. 445-450.

Venu, H., Raju, V. D. and Subramani, L. (2019). Combined effect of influence of nano additives, combustion chamber geometry and injection timing in a DI diesel engine fuelled with ternary (diesel-biodiesel-ethanol) blends. Energy, 174, pp. 386-406.
Venu, H., Subramani, L. and Raju, V. D. (2019). Emission reduction in a DI diesel engine using exhaust gas recirculation (EGR) of palm biodiesel blended with $\mathrm{TiO} 2$ nano additives. Renewable Energy, 140, pp. 245-263.

Vignesh, R. et al. (2019). Management of Complicated Crown-Root Fracture by Extra-Oral Fragment Reattachment and Intentional Reimplantation with 2 Years Review. Contemporary clinical dentistry, 10(2), pp. 397-401.

Vijayashree P. J. (2019). In silico validation of the non-antibiotic drugs acetaminophen and ibuprofen as antibacterial agents against red complex pathogens. Journal of periodontology, 90(12), pp. 1441-1448.

Wang, Y. et al. (2019). Synthesis of Zinc oxide nanoparticles from Marsdenia tenacissima inhibits the cell proliferation and induces apoptosis in laryngeal cancer cells (Hep-2). Journal of photochemistry and photobiology. B, Biology, 201, p. 111624.

Wu, F. et al. (2019). Biologically synthesized green gold nanoparticles from induce growth-inhibitory effect on melanoma cells (B16). Artificial cells, nanomedicine, and biotechnology, 47(1), pp. 3297-3305.

Wu, S.-S., Yeh, T.-T. and Chuang, S. Y.(2007). Biomechanical Evaluation of a newly designed transpedicular place intravertebral support for the management of osteoporotic vertebral compression fractures (1B1 Orthopaedic \& Rehabilitation Biomechanics I). The Proceedings of the Asian Pacific Conference on Biomechanics: emerging science and technology in biomechanics, p. S25. doi: 10.1299/jsmeapbio.2007.3.s25. 